\title{
A visão contemporânea da Gestão nas organizações sem fins lucrativos
}

\author{
Marinalva Teles da Silva', Monica Maria Martins de Souza², Roberto \\ Regensteiner 3 , Salete Alves dos Santos ${ }^{4}$,
}

Recebido em: 06/02/2013. Aprovado em:12/04/2013. Disponibilizado em: 24/06/2013

\begin{abstract}
1. Marinalva Teles da Silva é graduada em Administração nas Faculdades Integradas Campos Salles.
2. Monica Maria Martins de Souza é doutora em Comunicação e semiótica pela PUC/SP e pesquisadora do Mediatel. Psicóloga, e jornalista, desenvolve atualmente estudos na relação entre as Organizações e a Antropologia com base na Teoria da Mídia. Mestra em Administração e Recursos Humanos pela Universidade Mackenzie. Especializada em Administração e Recursos Humanos. É professora da Universidade Paulista, UNIP, da Eniac (em Guarulhos, São Paulo) e da Fac. Integradas Campos Salles, em São Paulo nos cursos de Comunicação, Publicidade e Governança em Tecnologia da Informação.

3. Prof. Roberto Regensteiner é Mestre em Economia e Sistema da Informação Professor da FICS Fac. Integradas Campos Salles, Pesquisador, Parecerista da Revista Augusto Guzzo da qual Compõe o Corpo Editorial. Orienta Alunos de Graduação e Pós-graduação em Economia e SI.

4. Salete Alves dos Santos é graduada em Administração nas Faculdades Integradas Campos Salles.
\end{abstract}

\section{Resumo}

A melhoria nas formas de gestão das Organizações sem fins Lucrativos ganha relevância à medida que aumenta seu número e a importância do seu trabalho. A eficácia e eficiência da gestão das mesmas interessam tanto aos financiadores diretos como a toda sociedade. Com o objetivo de conhecer melhor a forma em que são geridas fizemos uma pesquisa qualitativa em seis organizações que atuam em diferentes segmentos sociais. A pesquisa consistiu na realização de entrevistas com gestores e representantes destas organizações. Pudemos constatar que os gestores precisam utilizar adequadamente as funções gerencias clássicas para administrar de forma competente os recursos disponíveis e alcançar os resultados pretendidos, assegurando, assim, a sobrevivência e crescimento dessas organizações.

Palavras-chave: Terceiro Setor, Gestão, Funções Gerenciais.

\begin{abstract}
The relevance in the way nomprofit organizations are managed grows in direct proportion as its numbers and the social importance of their work, grow. The effectiveness and efficiency of their management concern direct lenders and society as a whole. In order to better understand the way they are managed we undertook a qualitative research on six such organizations in different social segments. The research consisted of interviews with managers and representatives. We realized that managers need to use properly classical managerial functions in order to administer competently available resources and achieve the desired results, thus ensuring survival and growth of these organizations.
\end{abstract}

Keywords: Third Sector, Management, Managerial Functions 


\section{Introdução}

Atualmente o campo da gestão nas organizações sem fins lucrativos tem sido um dos temas que mais preocupam profissionais da área da Administração. Isso se deve às demandas sociais que tais entidades enfrentam no seu dia a dia. A complexidade dos problemas sociais e as diferenças sociais que penalizam parte significativa da sociedade brasileira demandam destas organizações um novo modo de olhar a realidade social e de encaminhar soluções, que contribuam para reduzir as diferenças e oferecer a população uma vida mais digna. Contudo, não basta apenas mudar a maneira de olhar a realidade social, mas também buscar uma nova compreensão da gestão para garantir a sustentabilidade dessas organizações, adotando métodos gerenciais que possam ir de encontro às necessidades organizacionais, tornando sua ação mais eficaz na vida das pessoas que pretendem beneficiar. Desta forma será possível mobilizar pessoas e garantir os recursos financeiros necessários, além de manter aceso o compromisso e a paixão que os fundadores promovem. Em face destas reflexões e do cenário apresentado, a pesquisa pretendeu verificar se haveria um modelo especifico de gestão para as organizações sem fins lucrativos.

O desenvolvimento social exige que as pessoas adotem uma visão nova, sistêmica, redefinindo-se responsabilidades e adquirindo conhecimento, numa sociedade em que crescem as parcerias entre diferentes empresas e as organizações buscam desenvolver ações de interesse público. Vale ressaltar que as organizações têm complementado ações de responsabilidade do poder público e sua atuação é de suma importância para a sociedade, propiciando oportunidades para crianças, jovens e adultos, intervindo na educação, capacitação profissional, inclusão no mercado de trabalho, além de apoio psicológico e a tentativa de resgatar a estrutura familiar, entre outros objetivos.

Este artigo apresenta na Seção 2 os conceitos históricos das organizações sem fins lucrativos. $\mathrm{Na}$ Seção 3 é definido o conceito da gestão, a importância das funções gerenciais na gestão e o papel do gestor. A Seção 4 apresenta a metodologia utilizada na pesquisa. A Seção 5 mostra o resultado da pesquisa realizada em seis organizações e finalmente a seção 6 apresenta as considerações finais deste trabalho.

\section{Origem das Organizações sem fins Lucrativos}

Esta seção apresenta a origem das organizações sem fins lucrativos e os fatos relevantes que possibilitaram o surgimento e crescimento dessas organizações.

\subsection{Surgimento do Terceiro Setor no Âmbito Mundial}

Neste trabalho usamos a conceituação de que o Primeiro Setor é constituído pelo Estado, representado pelas prefeituras municipais, governos dos estados e a presidência da república, em resumo pelo "setor público". O Segundo Setor é o mercado, constituído pelo conjunto das empresas que exercem atividades privadas, ou seja, atuam em beneficio próprio e particular. O Terceiro Setor é um termo usado para fazer referência ao conjunto de sociedades privadas ou associações que atuam no país sem finalidades lucrativas, que tem como objetivo prestar serviços de caráter público. Podemos então dizer que nesse setor encontram - se todas as entidades conhecidas como filantropias, de 
caridade, ligadas as igrejas, fundações e as ONGs, entre outras.

Segundo Tenório (2002) as entidades do Terceiro Setor, "não fazem parte do Estado, nem a ele estão vinculados, mas se revestem de caráter público na medida em que se dedicam a causas e problemas sociais (...)".

O surgimento das organizações do Terceiro Setor ocorreu na Inglaterra, em 1601, no qual a Rainha Elizabeth I constituiu uma legislação para organizar o combate à pobreza, que era feito com recursos obtidos dos impostos pagos pelos Estados. Todavia esse documento, o "Estatuto dos Usos Caritativos", foi implantado na Velha Inglaterra e teve grande influência na Nova Inglaterra, parte do que iria formar mais tarde os Estados Unidos da América. A carência de recursos e instituições formais sentidas pelos novos imigrantes, além de pouca confiança em governos, ajudou a criar nos EUA um setor filantrópico. É importante ressaltar que na década de 70 os Estados Unidos começou a utilizar a expressão Terceiro Setor originouse do inglês "third sector", para identificar essas organizações. Enquanto isso na Europa Continental, tais organizações assumem a conotação de "não governamentais" destinadas a promover projetos de desenvolvimento social. Já na França, entre 1791 e 1901, as organizações passavam por momentos de hostilidade advindos de outros setores, nas quais eram considerados ilegais. As associações francesas tornaram-se legais no final do século XIX devido às modificações das leis do país. $\mathrm{Na}$ Itália, as entidades voluntárias sofriam com um estado burocrático suspeito e também com uma igreja de estilo resistente. No início do século XX, os conceitos em relação a essas instituições foram mudando, devido à permissão da igreja e mudanças para adquirir a formalidade.
O crescimento das organizações sem fins lucrativos sintetiza um marco primordial em todo o mundo, no qual Salamon citado por Madruga (1996) destaca como Revolução Associativa. As pessoas começaram a se conscientizar que era necessária a formação de instituições com objetivos totalmente sociais, em prol dos necessitados. No Brasil, as organizações inicialmente chamadas de entidades assistenciais, surgiram desde a colonização do Brasil. A partir dos anos 50 e 60 grande parte das organizações nasceu da força e expansão do sindicalismo brasileiro, denominadas Organizações Não Governamentais - ONGs.

Nos anos 70 o fenômeno "Terceiro Setor" ocorreu de forma expressiva e significativa na sociedade brasileira, ou seja, nortearam-se no Brasil protestos e manifestações contra o processo de ditadura militar e ao mesmo tempo a reivindicação aos direitos sociais. Com isso propiciou o surgimento de movimentos que buscavam ajuda mútua para garantir os direitos e consequentemente resultando em cidadania e solidariedade a todos. Nos anos 90 o interesse por esse setor cresceu, passou a ser realizado um estudo mais aprofundado através de centros de excelência como as Universidades Johns Hopkins e Harvard Business School. Neste período o cenário das organizações sem fins lucrativos latinos americanos se altera completamente, estas passam a viver a mais grave crise econômica desde que foram criadas. A mudança na forma de financiamento alterou a atuação das mesmas, a escassez de recursos das agências de cooperação internacional ${ }^{1}$, criou um cenário que levou a necessidade de gerarem recursos próprios e lutarem pelo acesso aos fundos públicos. Houve a necessidade de alterarem seus

\footnotetext{
1 Agência de Cooperação Internacional são organismos que atuam junto à promoção de cooperação bilateral e multilateral.
} 
procedimentos para sobreviver, e buscar a autossuficiência financeira.

Para fortalecer essa atuação Tenório diz: "Num espaço de tempo muito curto, o mundo se viu diante de problemas globais cujas soluções agora dependem da capacidade de articulação de um espectro mais amplo de agentes sociais" (2001, p.12). Nesta mesma época surgem então as "parcerias" que se integram, ou seja, o Estado, o mercado e as organizações sem fins lucrativos. Através dessa parceria tornase possível à mobilização de recursos para iniciativas de interesse público. Nesse momento o Estado adquire personalidade representativa e começa a observar as organizações sem fins lucrativos de uma forma mais amistosa, tendo por objetivo fundamental utilizar inúmeras ferramentas inovadoras para tentar resolucionar as diversidades existentes no âmbito social. Esse momento, de apoio do Estado, faz com que o mercado passe a ter uma visão diferenciada perante as organizações sem fins lucrativos, pois visavam somente $\mathrm{o}$ "lucro", e a partir de então passaram a ver essas organizações com outros olhos. Dirigentes, gestores e diretores passaram a investir mais recursos na área social.

Não podemos esquecer que na década de 90, o Terceiro Setor brasileiro, apresentou como marco um projeto "Ação da Cidadania contra Fome, a Miséria e pela Vida”, idealizado pelo sociólogo Herbert de Souza, o Betinho ${ }^{2}$. Sempre acreditou nas pessoas e achava que com a organização da sociedade, mesmo que de modo simples, era possível mudar a realidade do país. As empresas só valeriam a pena se tivesse como objetivo mudar a vida das pessoas. Herbert de Souza foi um dos responsáveis pela mobilização

\footnotetext{
$2 \quad$ Segundo Ibase, o arquivo de Betinho está no Centro de Pesquisa e Documentação de História Contemporânea do Brasil (CPDOC) da Fundação Getúlio Vargas (FGV).
}

em torno da luta contra a Fome e a Miséria no Brasil, além de fundador do Instituto Brasileiro de Análises Sociais e Econômicas - Ibase.

\section{Papel do Gestor}

O gestor deve garantir os resultados por meio da melhor aplicação dos recursos disponíveis, além de apresentar características essenciais para que possa desempenhar adequadamente o seu papel, sendo elas: facilidade na comunicação, liderança, capacidade de analisar o contexto interno e externo, pensar o futuro de forma estratégica, além das habilidades de viabilizar e estimular a equipe, poder de negociação e de convencimento, capacidade de tornar a gestão transparente. Para Hudson (1999), até a metade da década de 70 , administração não era muito usada pelas pessoas ao referiremse a organizações do Terceiro Setor. Era vista como parte do mundo dos negócios, e não para organizações voltadas para valores com características sociais. Este ponto de vista mudou com o crescimento do Terceiro Setor, que passou a necessitar de mão de obra cada vez mais qualificada.

De acordo com Tenório (2002), para superar os desafios que podem ameaçar a existência de uma organização sem fins lucrativos, estas tem que adotar novos instrumentos de gestão utilizando conhecimentos, habilidades e atitudes que assegurem o cumprimento dos objetivos organizacionais. Para o autor acima citado, as funções essenciais ao ato de gerenciar (planejamento, organização, direção e controle/avaliação) não podem existir independentemente uma da outra "porque representam a totalidade do trabalho do gerente".

O que se alcança é "uma gestão moderna que busque otimizar os recursos disponíveis a atender às expectativas da 
sociedade". Para Cunha (2011, p.81), "administração é o método do emprego eficiente de todos os recursos disponíveis (físicos, financeiros, técnicos e humanos) objetivando alcançar os resultados esperados". Como uma empresa privada, as organizações sem fins lucrativos devem ser bem gerenciadas, do ponto de vista dos recursos humanos, financeiros e materiais para o bom desenvolvimento dos projetos, programas e conquista de novas parcerias para sua sustentabilidade.

$\mathrm{Na}$ gestão todos os setores estão envolvidos, dentre eles, funcionários, conselheiros, apoiadores e parceiros. Sem esta parceria as tarefas do dia a dia, estarão sujeitos a enfrentar vários problemas ou deixar de ser realizadas. "Tratar todos os colaboradores e suas ideias com atenção, dando-lhes autonomia e reconhecendo suas iniciativas e realizações" (Diretoria Unibes, 2012, p.15). ${ }^{3}$ É necessário que o processo seja participativo e que receba contribuição de todos. O gestor deverá analisar a realidade social, econômica e política, além de identificar as forças atuantes desses campos, pois, são grandes influências na implantação do projeto e na prestação de serviços que se pretende realizar com a comunidade. Como observa Tenório (2002), as ONGs "exercem a gestão tendo por base a intuição e o bom senso, carecendo de embasamento técnico em administração".

O autor acima citado ressalta a importância da administração pelo fato de que estas organizações são "grupamento de pessoas e recursos - dinheiro, equipamentos, materiais, informações e tecnologia - como o objetivo de produzir bens e/ou prestar serviços e, portanto passíveis de gerência das partes que constituem, ou seja, deve-se haver a preocupação em estabelecer ou interpretar objetivos e de alocar recursos para atingir

3 Unibes (União Brasileiro - Israelita do Bem - Estar Social). uma finalidade previamente determinada". Sobre essa flexibilidade para as mudanças, Cunha (2011, p.36) diz que estratégias equivocadas, resistência a mudanças inevitáveis, discordância de rumos na alta direção, atritos e conflitos, são fatores contributivos para o fim da organização.

\subsection{A importância das funções gerenciais}

Precisa-se entender dentro da gestão o que significa planejar, organizar, dirigir, controlar e avaliar as atividades e os recursos de uma organização de forma equilibrada. Utilizando essas funções corretamente, as organizações terão seus recursos financeiros, humanos e materiais bem alocados para se alcançar os resultados pretendidos. A gerência comprometida em atingir os resultados, deve utilizar-se segundo Tenório (2001), de quatro funções gerenciais primordiais: planejamento, organização, direção e controle/avaliação. $\mathrm{O}$ autor reitera que essas funções devem ser entendidas como um ciclo que se repete dentro da organização. Segundo Tenório (2009, p.17), "Gerenciar é a ação de estabelecer ou interpretar objetivos e de alocar recursos para atingir uma finalidade previamente determinada". De acordo com o autor acima citado, utilizar-se das funções gerenciais, é a única forma de sobrevivência das referidas organizações. Contudo elas possuem um grande desafio: avançar no campo da gestão social. As funções gerenciais são primordiais para o crescimento da organização, transformando-se em valiosas ferramentas para o gestor:

a) Planejamento - Decidir ou escolher os objetivos organizacionais e estabelecer estratégias para alcançá-los;

b) Organização - Decidir que recursos e atividades são necessários para atender os objetivos, criar grupos de trabalho, atribuir autoridade e responsabilidade; 
c) Direção - Direcionar as atividades da equipe, comunicando-se, motivando-os e dirigindo-os para que se cumpram as metas estabelecidas;

d) Controle/Avaliação _ $\quad$ Estabelecer padrões, medir o desempenho planejado segundo critérios fixados e assegurar- se de que seja atingido.

\section{Metodologia}

Buscando atingir o objetivo principal desta pesquisa, utilizou-se um método qualitativo baseado em pesquisas bibliográficas, entrevistas e análise documental para a execução do tema da presente proposta. A pesquisa qualitativa costuma ser direcionada e não busca enumerar ou medir eventos e, geralmente, não emprega instrumental estatístico para análise de dados; seu foco de interesse é amplo e dela faz parte a obtenção de dados descritivos mediante contato direto e interativo do pesquisador com a situação e com o objeto de estudo. Neste tipo de pesquisa é possível apreender elementos que uma pesquisa quantitativa não fornece. $\mathrm{O}$ roteiro construído norteou a entrevista e ajudou a responder às questões formuladas neste trabalho.

Para obtenção dos dados empíricos foi aplicada uma entrevista semi - estruturada para buscar respostas aos questionamentos. De acordo com Colauto e Beuren (2006, p.132) "a entrevista semi - estruturada permite maior interação e conhecimento das realidades dos informantes". Esse tipo de entrevista combina perguntas abertas e fechadas, onde o informante tem a possibilidade de discorrer sobre o tema proposto. As técnicas desse tipo de entrevista têm como vantagem a sua elasticidade quanto à duração e permite profunda cobertura sobre o assunto. Ao contrário dos questionários enviados por correio que tem baixo índice de devolução, a entrevista apresenta um índice de respostas mais abrangente.

Segundo Martins (Revista de Contabilidade e Organizações FEARP/USP 2008) a análise e as reflexões estão presentes nos vários estágios da pesquisa, particularmente no levantamento das informações, nos dados e evidências que compõem os resultados parciais.

Estes instrumentos de pesquisa foram utilizados de forma exploratória, com o intuito de se obter um resultado eficaz.

\section{Apresentação e análise dos resultados}

Constatou-se no universo pesquisado que nem todas as entidades utilizam-se das funções gerenciais, o que confirma aquilo que foi evidenciado no referencial teórico pesquisado. O não uso das ferramentas planejamento, organização, direção e controle/avaliação - comprometem a eficiência e a eficácia de qualquer projeto que venha a ser desenvolvido dentro da instituição. As organizações pesquisadas atuam em diversas áreas sendo que 100\% delas atuam também na área de educação. Percebe-se grande preocupação dessas organizações na educação. Segundo o dicionário Aurélio, educação é o "processo de desenvolvimento da capacidade física, intelectual e moral da criança e do ser humano em geral, visando à sua melhor integração individual e social"'. Identificamos que todas possuem uma missão bem definida, sabem claramente onde estão e onde querem chegar, tendo como base a capacidade de recursos disponíveis, humanos, financeiros e materiais. Todas trabalham com mão - de - obra remunerada e voluntária, aproximadamente 1.283 são funcionários CLT e 561 são voluntários. 
Estes números mostram o crescimento acelerado do Terceiro Setor e cada vez mais há necessidade dessas organizações serem gerenciadas de forma técnica e profissional, não sendo suficiente a sobrevivência da entidade somente com voluntários. Nesse sentido, Tenório (2001), aponta a necessidade de profissionalização dos indivíduos que atuam na área social, sobretudo daqueles que desempenham papéis gerenciais. Sugere-se que a organização em parceria com o Sistema Brasileiro de Apoio às Micro e Pequenas Empresas (SEBRAE), ou outras empresas que oferece este tipo de conhecimento, propiciem cursos de capacitação aos gestores das entidades ligadas ao Terceiro Setor.

Observou- se em quase todo universo pesquisado, a preocupação dessas organizações terem em seus quadros de funcionários pessoas capacitadas para exercer as funções estabelecidas. Muitas delas têm oferecido cursos, bolsas de estudo em universidades para os colaboradores. Nos cargos que englobam a gestão, os colaboradores possuem formação superior completo ou em andamento.

Todos se mostraram motivados nas funções que exercem, tanto funcionários como voluntários. Segundo os entrevistados, a captação de recursos ainda tem sido um dos grandes desafios do Terceiro Setor. Mesmo em meio a tantas dificuldades enfrentadas têm alcançando resultados relevantes. Percebeu - se uma maior dificuldade na captação de recursos financeiros e humanos nas entidades com menos tempo de atividade, essa carência está diretamente ligada à falta de experiência e conhecimento dos dirigentes. Deve-se estar constantemente revendo e acompanhando os processos organizacionais para que em tempo hábil possa redirecionar os rumos, de acordo com os objetivos estabelecidos.
Em todas as organizações pesquisadas predomina a gestão participativa, pois acreditam que enriquece o processo de amadurecimento do grupo, além de trazer grandes resultados para o desenvolvimento da organização. Cinco das seis organizações pesquisadas tem nos convênios com órgão público a maior parte da receita. Apenas uma organização tem no recebimento de donativos diversos de doadores (associados) a o maior percentual das receitas.

Constatou-se que a divulgação das atividades é feita através de parceria com a mídia, publicações em revistas, jornais e o próprio site da instituição, sendo que apenas três organizações, possuem orientação de uma assessoria de imprensa. Segundo a presidente de uma das organizações, uma das decisões tomadas na mudança de gestão foi o olhar exterior, ou seja, precisavam do apoio de uma agência de publicidade para ajudá-los na revitalização do nome, posteriormente vindo a adotar um nome fantasia.

O marketing dessas organizações tem sido o da estratégia de mudança social, propondo novos comportamentos, atitudes e práticas na sociedade. Sabe-se que algumas empresas fazem doações como estratégia de venda, destinando parte dos recursos para instituições. Há também empresas que fazem uso da filantropia como promoção institucional, estreitando laços com a comunidade, governo e outros parceiros. Não se pode esquecer que todas estas atividades de marketing, em prol das organizações sem fins lucrativos, refletem fortemente em sua imagem despertando a atenção e o interesse da sociedade. A realidade atual requer do dirigente dessas organizações conhecimentos técnicos, pois cabe a ele criar mecanismos sólidos para a sobrevivência e desenvolvimento da mesma, deve-se ter uma harmonia entre o técnico e o social. Conforme mencionado pela 
presidente Maria Luiza d'Orey Espírito Santo da Instituição Liga Solidária:

(...) Quando o nosso grupo assumiu, em abril de 2006, já tínhamos, portanto, algum conhecimento do enorme desafio que teríamos que enfrentar para que a Liga pudesse continuar fazendo o que sempre fez: vencer os desafios sociais específicos do momento. Sendo assim, teríamos que adequá-la aos novos tempos, complexos e difíceis. Mudar para proteger os valores essenciais de amor e de compaixão que sempre a nortearam, sem deixar de lado a eficiência, a transparência, o comprometimento e a ética.

Percebendo essa necessidade a organização trouxe um gestor com uma ampla visão técnica começando pela reavaliação de missão, visão e valores, em seguida "trouxe vida" ao nome da organização com o apoio de uma agência de publicidade, sendo que de Liga das Senhoras Católicas de São Paulo, passou para o nome fantasia Liga Solidária, que atualmente tem ajudado muito na comunicação com todos os agentes externos. Verifica-se que as mesmas dificuldades enfrentadas nas organizações com fins lucrativos, também são enfrentados nas organizações não governamentais que tem objetivos atender as necessidades sociais das pessoas. Nas palavras do atual presidente da Unibes, Bruno Laskowsky (2011), é mencionado a nova visão que tiveram que adotar devido as dificuldades e desafios enfrentados:

Adicionamos um novo conteúdo de políticas gerenciais aprendidas no mundo 'empresarial' e as adaptamos/ajustamos para que fossem assimiladas e melhoradas pela Instituição (...). A nova visão que imprimimos à entidade une gestão e governança - alinhadas às melhores práticas do mundo corporativo - ao amor dos voluntários e dos que dirigem a Unibes. Com isso, os diretores executivos ganharam sensibilidade social e os profissionais e voluntários da área social adquiriram ferramentas de gestão.

Observa-se acima que as políticas de uma organização podem mudar conforme a necessidade da organização, a essência é a mesma, é necessário um período de adaptação e ajustar as mudanças dentro do processo que atualmente é executado.

Sabe-se que os pilares propostos pelas boas práticas de governança corporativa são a transparência, equidade, prestação de contas e responsabilidade corporativa. A implementação das boas praticas de governança corporativa possibilita uma gestão. Na pesquisa realizada verificou-se que mesmo nas entidades com menos tempo de atividade, seus dirigentes têm presenciado na prática a necessidade de se utilizar as ferramentas gerenciais e ajusta-las a realidade do Terceiro Setor. Abrir uma organização sem fins lucrativos não é algo simples, muitos querem, mas não reúnem condições suficientes para isso, é como abrir uma empresa e no caso de uma ONG os recursos são escassos e deve-se ser eficiente para fazer muito mais, com o pouco que têm, e para que isso aconteça é necessário entender do assunto e saber quais os desafios que o espera. $\mathrm{O}$ inicio de qualquer coisa requer muita dedicação e tempo disponível. É possível dar inicio a abertura de uma organização sem fins lucrativos, mas para que ela não venha a naufragar, é necessário começar certo, como por exemplo, elaborando um "Plano de Negocio". $\mathrm{Na}$ elaboração do plano deverá conter:

a) Finalidade da instituição, o que motivou os integrantes a escolher o segmento;

b) Análise social, ou seja, qual o benefício gerará e a quem irá beneficiar, além de pesquisar qual a ONG existente na 
região e os programas, sua aceitação e alcance que tem na região;

c) Verificar os pontos que requererá maior atenção, principalmente a localização e estrutura física as sede, se serão adequadas ao desenvolvimento das atividades, sempre analisando as reais necessidades do público que se pretende atingir;

d) Quais as pessoas terão interesse em financiar as atividades da instituição;

e) A instituição trabalhará com a venda de produtos para viabilizar suas atividades;

f) Estabelecerá contratos/convênios com o poder público, sendo necessário verificar as exigências estatutárias e a forma de constituição da ONG, além dos requisitos para a isenção ou imunidade tributária;

g) Somente os integrantes/dirigentes serão suficientes, ou será necessário contratar pessoas e por qual salário;

h) Contará com o trabalho voluntário, de que forma;

i) Como será divulgada a organização, para que fique conhecida entre a sociedade;

j) Será necessário relacionar o investimento necessário para dar inicio as atividades, locação ou compra do imóvel, equipamentos, instalações físicas, entre outros;

k) Gastos com a formalização da ONG;

1) Principalmente o Planejamento Anual, ou seja, no primeiro ano de vida relacionar as despesas e receitas mensalmente.

Verifica-se que um Plano poderá agregar um inicio com uma base sólida e evitar que futuramente esta instituição venha fracassar. Não se sugere que o gestor seja um especialista, mas que busque conhecimentos, não adianta ter uma missão boa e não ter uma transparência contábil, através dela é que será garantido o financiamento para as atividades desempenhadas pela organização. É necessário saber como gerar negócios, como extrair da sociedade recursos e devolver a ela produtos e serviços.

\section{Considerações Finais}

No decorrer deste trabalho buscou-se mostrar a importância de se aplicar as ferramentas gerenciais nas organizações sem fins lucrativos. Procuramos contextualizar o surgimento do Terceiro Setor e os desafios enfrentados, mostrando as atuais necessidades dessas organizações, sem excluir o valor e a essência que elas trazem desde o seu surgimento. Se na década de 70 tinha-se uma visão missionária - caritativo que predominava, na década de 90 a visão era outra, ou seja, atuação social, mas com foco na gestão, despertando um grande interesse por esse setor, a ponto de serem realizados estudos mais aprofundados nas universidades de renome.

As organizações sociais já não eram mais vistas como uma ameaça, mas como um parceiro para complementar as ações que o poder público jamais conseguiria realizar sozinho. Percebemos que à medida que o Terceiro Setor crescia, o Estado foi "cedendo espaço" para essas organizações, criando a partir de então leis que vieram agregar valor, reconhecimento e possibilidades para a continuidade das atividades. Foi possível verificar a grande influência que tiveram as igrejas através do trabalho voluntário, pois foram os principais fundadores dessas organizações que tem mudado a vida de milhares de crianças, jovens e adultos. $O$ voluntariado foi imprescindível para reunir e chegar até as pessoas necessitadas, identificar suas necessidades e transformar esses fatos em 
ações que mobilizou não somente o poder público, mas empresas privadas e indivíduos.

Pode-se dizer que os resultados obtidos neste trabalho, cumpriram o propósito que foi o de demonstrar a importância da gestão nas organizações sem fins lucrativos. Temos consciência de que os dados apresentados não podem e nem devem ser generalizados, mas terminamos este trabalho com a certeza de que o processo desenvolvido pelas organizações pesquisadas está dentro das necessidades do Terceiro setor. Não existe um modelo único de gestão a ser aplicado neste perfil de organização. Contudo, acreditamos que a forma como os métodos gerenciais são aplicados é o que fará a diferença para o sucesso da organização. Se no inicio de sua existência houve uma elaboração de um "Plano de Negócio" provavelmente as chances de sua permanência na sociedade será grande. É importante salientar que o trabalho voluntário deve ser visto como um apoio fundamental para o desenvolvimento da organização, mas não é suficiente para estruturá-la, exige dedicação e uso adequado das habilidades e conhecimento dos dirigentes.

\section{Referências Bibliográficas}

1. COlauto, R. D.; BEUREN, I. M. Coleta, análise e interpretação dos dados. In: BEUREN Ilse Maria (org). Como Elaborar Trabalhos Monográficos em Contabilidade. 3. ed. São Paulo: Atlas 2008.

2. CUNHA JUNIOR, Oscar. Desenvolvimento Organizacional: Fundamentos e Conceitos Básicos. São Paulo: NC, 2011.

3. HUDSON, Mike. Administrando Organizações do Terceiro Setor. São Paulo: Makron Books,1999. Disponível em:<http://www.anaceu.org.br/conteudo/a rtigos/publicacoes $/ 27 \% 20-\% 20$ Publicacoes
$\% 20 \% 20$ Vanauey $\% 20$ Ferreira $\% 20$ Vieira.pdf >. Acesso em: 03 jul. 2012

4. MADRUGA, Venturini. A vivência do planejamento estratégico em uma organização terceiro setor: o caso da Omep/Sm. 2004. Disponível em: http://www.ead.fea.usp.br/ Semead/ 7 semead/paginas/ artigos\%20recebidos/ terceiro $\% 20$ Setor/TS01 - a vivencia do planejamento terceiro do setor. PDF. Acesso em: 02 de Agosto de 2012.

5. MORABIA, Mirella; BELLIS, Sarita; GERMANALANGONE (Ed.). Paralelos: 95 anos de Unibes contados através da História de São Paulo. São Paulo: Narrativa Um, 2011.

6. SALAMON, Lester. Estratégias para o fortalecimento do Terceiro Setor. Conferência proferida durante o III Encontro Ibero-Americano para o Terceiro Setor, Rio de Janeiro, 1996

7. TENÓRIO, F. Gestão de ONGS: principais funções gerenciais. Rio de Janeiro: FGV, 2009.

8. VANESSA OLIVEIRA (São Paulo) (Ed.). Liga Solidária: Relatório de Atividades. São Paulo, 2011. Disponível em: <http://www.ligasolidaria.org.br/relatorios /relatorio2011.pdf>. Acesso 02/08/12.

9. http://veja.abril.com.br/acervodigital/ home.aspx . Acesso em 20. ago.2012

10. http://www.comunidadesolidaria.org.br. Acesso em 20.ago.2012

11. http://abong.org.br/.Acesso em 20.fev. 2012

12. http://www.educarparavida.com.br. Acesso em 02. fev.2012

13. http://www.institutogrpcom.org.br . Acesso em 02. fev.2012

14. http://www.terceirosetoronline.com.br. Acesso em 02. fev.2012 